IZA DP No. 5350

Accounting for Labor Demand Effects in Structural Labor Supply Models

Andreas Peichl

Sebastian Siegloch

November 2010 


\title{
Accounting for Labor Demand Effects in Structural Labor Supply Models
}

\author{
Andreas Peichl \\ IZA, University of Cologne, ISER and CESifo \\ Sebastian Siegloch \\ IZA and University of Cologne
}

\author{
Discussion Paper No. 5350 \\ November 2010
}

\author{
IZA \\ P.O. Box 7240 \\ 53072 Bonn \\ Germany \\ Phone: +49-228-3894-0 \\ Fax: +49-228-3894-180 \\ E-mail: iza@iza.org
}

\begin{abstract}
Any opinions expressed here are those of the author(s) and not those of IZA. Research published in this series may include views on policy, but the institute itself takes no institutional policy positions.

The Institute for the Study of Labor (IZA) in Bonn is a local and virtual international research center and a place of communication between science, politics and business. IZA is an independent nonprofit organization supported by Deutsche Post Foundation. The center is associated with the University of Bonn and offers a stimulating research environment through its international network, workshops and conferences, data service, project support, research visits and doctoral program. IZA engages in (i) original and internationally competitive research in all fields of labor economics, (ii) development of policy concepts, and (iii) dissemination of research results and concepts to the interested public.
\end{abstract}

IZA Discussion Papers often represent preliminary work and are circulated to encourage discussion. Citation of such a paper should account for its provisional character. A revised version may be available directly from the author. 
IZA Discussion Paper No. 5350

November 2010

\section{ABSTRACT}

\section{Accounting for Labor Demand Effects in Structural Labor Supply Models*}

When assessing the effects of policy reforms on the labor market, most studies only focus on labor supply. The interaction of supply and demand side is not explicitly modeled, which might lead to biased estimates of potential labor market outcomes. This paper proposes a straightforward method to remedy this shortcoming. We use information on firms' labor demand behavior and feed them into a structural labor supply model, completing the partial analysis of the labor market on the microdata level. We show the performance and relevance of our extension by introducing a pure labor supply side reform, the workfare concept, in Germany and simulating the labor market outcome of the reform. We find that demand effects offset about 25 percent of the positive labor supply effect of the policy reform.

JEL Classification: J22, J23, J68

Keywords: labor supply, labor demand, policy reform, workfare

Corresponding author:

Sebastian Siegloch

IZA

P.O. Box 7240

53072 Bonn

Germany

E-mail: siegloch@iza.org

\footnotetext{
* Andreas Peichl is grateful for the financial support from the Deutsche Forschungsgemeinschaft DFG (PE1675). We would like to thank Olivier Bargain, Stefan Boeters, Dan Hamermesh, Nicolas Herault, Herwig Immervoll, participants of the 1st Essex microsimulation workshop as well as seminar participants at IZA for helpful comments and suggestions. The usual disclaimer applies.
} 


\section{Introduction}

Labor supply elasticities are important ingredients for policy evaluation (see, e.g., Blundell et al. (2000) for a partial equilibrium application and Bovenberg et al. (2000) for a general equilibrium model). Furthermore, they crucially affect the optimal design of tax systems (see, e.g., Saez (2001), Immervoll et al. (2007) and Blundell et al. (2009)). The elasticities are usually derived using some sort of (structural or reduced form) labor supply model (see, e.g., Aaberge et al. (1995, 1999, 2000), Hoynes (1996), Eissa and Hoynes (2004) and Heim (2007, 2009)). All these studies have in common that they focus only on the supply side implicitly assuming perfectly elastic labor demand. Only then labor supply effects equal eventual employment effects. However, as the extensive empirical evidence suggests, labor demand is usually somewhat elastic (Hamermesh (1993)). Hence, labor market estimates stemming from pure labor supply models are almost surely biased and inference based on them is consequently flawed.

In this paper, we develop a straightforward approach to extend random utility models of labor supply explicitly to take into account demand effects by iterating labor supply and demand until the partial labor market equilibrium is reached. Our approach is related to work of Creedy and Duncan (2005) as well as Haan and Steiner (2006). In both studies information on labor demand is used to calculate wage adjustments after some kind of labor supply shift. The authors of the former study employ the concept of aggregate labor supply to determine the effects of proportional wage changes. In contrast, Haan and Steiner (2006) model labor supply responses and wage adjustments at the individual level.

We augment the original methods in several ways. Firstly, instead of relying on labor demand elasticities from the literature, we estimate own labor demand functions for different types of workers, based on rich, linked administrative employeremployee data. By doing that, we remain at the microdata level as the detailed administrative firm dataset allows the identification of precise labor demand reactions to wage changes for different labor inputs (i.e. household-type/skill cells). In addition, our iteration process guarantees that households individually face possible demand restrictions depending on their characteristics. Hence, we capture the full heterogeneity of the microdata sample. Finally, neither Creedy and Duncan (2005) nor Haan and Steiner (2006) provide much evidence on how the interaction of supply and demand side functions. We open the black box and give detailed insight on 
both the iteration process itself and its theoretical plausibility.

We also see several advantages of our approach compared to alternative methods of incorporating labor demand effects in labor supply estimations, such as computable general equilibrium (CGE) models (see Peichl (2009) for an overview) or models integrating demand side restrictions via probabilities (cf. Blundell et al. (1987)). Our model is slender and parsimonious, since it focuses only on the labor market. At the same time, we can introduce much more heterogeneity, as both supply and demand side are estimated using microdata. Moreover, we explicitly model the interaction of demand and supply, taking firm behavior into account and separating it from labor supply effects.

In order to demonstrate the performance of our newly developed supply-demand link, we depart from a standard, discrete choice, structural labor supply model following van Soest (1995) and Blundell et al. (2000). We estimate the model with the 2009 wave of German Socio-Economic Panel Study (GSOEP), a representative, microdata, household panel study, using the IZA tax benefit calculator IZA $\Psi$ MOD to transform gross income to net income. As a counterfactual policy reform, we introduce a workfare concept (see Besley and Coate (1992) and Moffitt (2002)). Every employable individual living in a household that receives unemployment benefits has to fulfill a work requirement equivalent to a full-time job. We choose this specific counterfactual mainly because it is expected to have a substantive positive labor supply effect and because it is often criticized for ignoring demand side restrictions. Furthermore, the effect on the government budget is expected to be positive, making the reform feasible from a fiscal point of view.

Our simulation results show that demand effects do indeed play an important role. They offset the positive labor supply reaction of the workfare reform by 25 percent (equivalent to 380,000 full-time jobs). Thus, labor demand works as a stabilizer to labor supply shifts - just as a trivial illustration of a supply/demand model would suggest. To check the robustness of our results, we simulate other different counterfactuals. We find demand effects of comparable sizes in relative terms. Moreover, the stabilizing effect also works in the other direction, that is, if a reform reduces labor supply, the incorporation of labor demand effects countervails the negative supply effects, making the overall employment effect less negative. Further sensitivity tests show that, in line with the theory, the higher the demand elasticity, the smaller the demand adjustments.

The paper is structured as follows. Section 2 compares our method to the liter- 
ature. In Section 3, we set up a standard labor supply model. Section 4 describes the labor demand model. Section 5 demonstrates the linkage of labor supply and demand. Empirical results are presented and discussed in Section 6 and Section 7 concludes.

\section{Related literature}

There are other approaches to account for demand effects in labor supply models which are naturally related to ours. One common method, particularly in the field of ex-ante policy evaluation, is linking labor supply models with computable general equilibrium (CGE) models (see Bourguignon et al. (2003), Bovenberg et al. (2000), Boeters et al. (2005), Arntz et al. (2008), Boeters and Feil (2009) and Hérault (2010)). The advantage of our approach is that we overcome possible aggregation and linking problems in micro-macro models. ${ }^{1}$ Our analysis remains on the microlevel, as both the supply and demand side are estimated using microdata. This approach allows us to introduce much more heterogeneity into the analysis, since we do not rely on just a few representative agents, as is the case in CGE models. Moreover, we do not have to model further markets and impose assumptions on how, for example, a decline in consumption translates into a reduction of output. We adopt a partial framework and focus solely on the labor market. ${ }^{2}$

Another cluster of studies tries to extend structural labor supply models by introducing probabilities which account for possible demand side frictions. Within this line of literature, there is a whole range of different models, which can be broadly divided into three subgroups. Firstly, there are Double Hurdle Models (DHM), which assume a two-tier decision making process (see Blundell et al. (1987), Hogan (2004)

\footnotetext{
${ }^{1}$ When conducting such a micro-macro linkage, several potential problems arise. The main problem is the lack of theoretical and empirical consistency between the micro and macro components, which can give rise to biased results. To be able to successfully link MS and CGE models, there have to be some common variables through which the two models can exchange information. Although CGE models are based on the microeconomic general equilibrium theory, they usually use aggregated macrodata for the analysis. Hence, it is necessary to aggregate or disaggregate these variables to be comparable with the variables in the other model. Furthermore, it has to be checked whether the same variable in both models represents the same population (e.g. household consumption in the micro-model vs. aggregated total consumption, including government in the macro-model).

${ }^{2}$ On the other hand, our slender approach is not able to take into account general equilibrium effects (other than wage and employment changes): in particular, we ignore changes in consumption and consumer prices. Hence, if these responses are important, our approach is not able to capture the full effects of a policy change (but it still performs better than a pure labor supply model).
} 
and Bargain et al. (2010) for a recent empirical implementation for Germany). In the first stage, the individual decides whether to participate in the labor market or be inactive. The second hurdle is the probability of being involuntary unemployed, conditional on having chosen to participate in the labor market. This probability can be interpreted as a demand side restriction.

The second group of studies extends labor supply models to take classical nonemployment into account. Meyer and Wise $(1983 a, 1983 b)$ model the effects of a minimum wage on youth employment by introducing the probability that a worker is not productive enough to be hired. Laroque and Salanié (2002) extend this framework and include the probability of being involuntarily unemployed due to frictional or business-cycle related unemployment.

The third probability-based approach to integrate labor demand constraints is to restrict the set of hours which can be chosen by individuals. In those models, working hours generally stem from some sort of offer distribution (see Moffitt (1982), van Soest et al. (1990) and Aaberge et al. (1995)). Tummers and Woittiez (1991) extend those models by allowing the wage rate to vary with the offered hours. Bloemen (2000) generalizes hour offers to job offers which consist of both an hour and a wage component.

We see the advantage of our approach in the interplay of demand and supply which is explicitly modeled; whereas the probability based models focus on a pure supply model which is enriched by a demand side restriction. Moreover, none of the probability-based approaches takes firm behavior explicitly into account and isolates it from labor supply effects. Finally, and from a more general perspective, all of the aforementioned demand side restrictions are implicitly incorporated into our demand estimations.

\section{$3 \quad$ Labor supply model}

We construct a discrete choice, random utility model to estimate the labor supply behavior of individuals, based on a structural specification of preferences. The main advantage of this model over continuous ones is the possibility to account for non-linearities and non-convexities in the budget set. Those kinds of models have become quite standard in the last 15 years (see Aaberge et al. (1995), van Soest (1995) and Blundell et al. (2000)), and so we focus here on the fundamental, 
underlying assumptions for the estimation. ${ }^{3}$ Following van Soest (1995), we rely on a translog specification of utility. The (deterministic) utility of a couple household $i$ for each discrete choice $j=1, \ldots, J$ can be written as:

$$
\begin{aligned}
U_{i j}= & \alpha_{c i} \ln c_{i j}+\alpha_{h_{f} i} \ln h_{i j}^{f}+\alpha_{h_{m} i} \ln h_{i j}^{m}+\alpha_{h_{f f}}\left(\ln h_{i j}^{f}\right)^{2}+ \\
& \alpha_{h_{m m}}\left(\ln h_{i j}^{m}\right)^{2}+\alpha_{c c}\left(\ln c_{i j}\right)^{2}+\alpha_{c h_{f}} \ln c_{i j} \ln h_{i j}^{f}+ \\
& \alpha_{c h_{m}} \ln c_{i j} \ln h_{i j}^{m}+\alpha_{h_{m} h_{f}} \ln h_{i j}^{f} \ln h_{i j}^{m}+\beta_{f} D_{i j}^{f}+\beta_{m} D_{i j}^{m}
\end{aligned}
$$

with household consumption $c_{i j}$ and spouses' worked hours $h_{i j}^{f}$ (female) and $h_{i j}^{m}$ (male) and $D_{i j}^{m / f}$ being part-time dummies representing fixed costs of work. We assume seven discrete hours categories: 0, 10,20,30,40,50 and 60 hours for each individual. ${ }^{4}$ Hence, the $J=49$ choices in a couple correspond to all combinations of the spouses' working-time categories. Coefficients on consumption and worked hours vary linearly with several taste-shifters (for instance age, age squared, presence of children, region).

The direct utility function is estimated using McFadden's conditional logit model (McFadden (1973)), maximizing the probability that the household chooses the observed working-hour category, given its characteristics and its calculated consumption. In addition to this deterministic part, the household's random utility level depends on a stochastic error term. We calibrate the random part of the utility function by drawing error terms from the Extreme Value Type-I distribution in order to guarantee that the observed choices yield the maximum random utility (see Duncan and Weeks (1998) and Creedy and Kalb (2005)). ${ }^{5}$

The model is estimated on the German Socio-Economic Panel Study (GSOEP), which is a representative microdata household panel study (Wagner et al. (2007)). We select the 2010 wave of GSOEP, which contains information about the year 2009 . We observe around 25, 000 individuals in more than 12, 000 households. Among others, we draw the following data: gross wage, job type, government transfers, working

\footnotetext{
${ }^{3}$ It should be noted that the choice of the discrete labor supply model is irrelevant for the demand extension proposed later on.

${ }^{4}$ Our results are robust with respect to different discretizations and specifications of the utility function.

${ }^{5}$ Again, note that the eventual labor supply-labor demand link proposed in this paper is very general and does not depend on the derivation of the error terms. We obtain similar results when using other approaches, such as the analytical derivation of error terms proposed by Bonin and Schneider (2006a) or using the conventional frequency method (Aaberge et al. (1995) or van Soest (1995)).
} 
time, composition of household as well as age and education of household members. The latter information is particularly important for the demand extension, since we are able to assign different skill levels to individuals: High-skilled individuals hold a university, polytechnical or college degree. Medium-skilled workers have either completed vocational training or obtained the highest German high school diploma, called the Abitur. Unskilled workers have neither finished vocational training nor obtained the Abitur.

In order to translate gross earnings into consumption (equivalent to net income), we use the IZA tax benefit calculator, called IZAYMOD (see Peichl et al. (2010) for an overview). IZA $\Psi$ MOD comprises all relevant features of the German tax and benefit system, such as income taxation and social insurance contribution rules, as well as unemployment, housing and child benefits. ${ }^{6}$ Our calculations are representative for Germany by using the GSOEP population weights. For the labor supply estimation (and the eventual demand extension), we assume that certain individuals do not supply labor or have an inelastic labor supply (such as pensioners, people in education, civil-servants or the self-employed). By assumption, those groups do not adjust their labor market behavior due to a policy reform; they are nonetheless part of the sample (for the analysis of fiscal or distributional effects).

\section{Labor demand model}

\subsection{Empirical model and estimation}

For the demand model, we follow standard practice by adopting the dual approach and minimizing costs given a constant output (Hamermesh (1993)). We select a translog cost function, as proposed by Christensen et al. (1973), which is a linear, second-order approximation to an arbitrary cost function. The translog cost function belongs to the class of flexible cost functions, which do not restrict the substitution elasticities of input factors, and is therefore preferable to Cobb-Douglas or Constant Elasticity of Substitution functions. ${ }^{7}$

We follow the concrete specification proposed by Diewert and Wales (1987) and

\footnotetext{
${ }^{6}$ We apply the rules as of January 2009.

${ }^{7}$ See Peichl and Siegloch (2010) for more details on the choice of cost functions.
} 
calculate the short-term $\operatorname{costs} C$ of a firm, given a certain output $Y$, as follows ${ }^{8}$ :

$$
\begin{gathered}
\ln C\left(w_{i}, Y\right)=\alpha_{0}+\sum_{i=1}^{n} \alpha_{i} \ln w_{i}+0.5 \sum_{i=1}^{n} \sum_{j=1}^{n} \alpha_{i j} \ln w_{i} \ln w_{j}+ \\
\beta_{Y} \ln Y+\sum_{i=1}^{n} \beta_{i Y} \ln w_{i} \ln Y+0.5 \beta_{Y Y}(\ln Y)^{2} \\
\delta_{t} t+\sum_{i=1}^{n} \delta_{i t} t \ln w_{i}+0.5 \delta_{t t} t^{2}+\delta_{t Y} t \ln Y
\end{gathered}
$$

where $w_{i}$ denotes unit costs (i.e. the wage) of the $i^{t h}$ labor input and $t$ is a time index. ${ }^{9}$ Besides the condition $a_{i j}=a_{j i}$, several other restrictions on the parameters hold, granting linear homogeneity in factor prices and allowing for non-constant returns to scale:

$$
\sum_{i=1}^{n} \alpha_{i}=1 \quad \sum_{i=1}^{n} \alpha_{i j}=\sum_{j=1}^{n} \alpha_{i j}=0 \quad \sum_{i=1}^{n} \beta_{i Y}=0 \quad \sum_{i=1}^{n} \delta_{i t}=0
$$

By Shephard's lemma (see Shephard (1970)) the first-derivative of the cost function with respect to a specific factor price yields the demand for this input, $X_{i}=\frac{\partial C}{\partial w_{i}}$. Exploiting the fact that the cost function is logarithmized and thus that $\frac{\partial \ln C}{\partial \ln w_{i}}=\frac{\partial C}{\partial w_{i}} \frac{w_{i}}{C}$, we derive the cost shares:

$$
S_{i}=\frac{w_{i} X_{i}}{C}=\frac{\partial \ln C\left(w_{i}, Y\right)}{\partial \ln w_{i}}=\alpha_{i}+\sum_{j=1}^{n} \alpha_{i j} \ln w_{j}+\beta_{i Y} \ln Y+\delta_{i t} t
$$

It is straightforward to calculate labor demand elasticities from the cost share. The own-wage elasticity is defined as:

$$
\bar{\mu}_{i i}^{T L}=\frac{\alpha_{i i}-\widehat{S}_{i}+\widehat{S}_{i} \widehat{S}_{i}}{\widehat{S}_{i}}
$$

${ }^{8}$ Time and firm indices have not been included for increased clarity.

${ }^{9}$ As we are estimating short-term labor demand function and since there is no direct measure of capital in the firm data, we assume separability between labor and capital. In fact, robustness checks have shown that the inclusion of capital, approximated by investments in the preceding year hardly changes the estimated own-wage elasticities. 
and the cross-wage elasticity yields:

$$
\bar{\mu}_{i j}^{T L}=\frac{\alpha_{i j}+\widehat{S}_{i} \widehat{S}_{j}}{\widehat{S}_{i}}
$$

To each of the $n$ share functions, a disturbance term $\varepsilon_{i}, i=1, . ., n$, is added. It is assumed that the resulting disturbance vector $\varepsilon=\left\{\varepsilon_{1}, \ldots, \varepsilon_{n}\right\}$ is multivariate and normally distributed, with mean vector zero and constant covariance matrix. Since the share functions add up to unity, one equation is dropped by using the restrictions (3) and the relation $S_{i}=1-\sum_{j \neq i} S_{j}$.

Assuming three different types of labor inputs (subindex 1 for high-skilled, 2 for medium-skilled and 3 for unskilled labor), we arrive at the system of share equations to be estimated:

$$
\begin{aligned}
& S_{2}=\alpha_{2}+\alpha_{22} \ln \left(\frac{w_{2}}{w_{1}}\right)+\alpha_{23} \ln \left(\frac{w_{3}}{w_{1}}\right)+\beta_{2 Y} \ln Y+\delta_{2 t} t+\varepsilon_{2} \\
& S_{3}=\alpha_{3}+\alpha_{32} \ln \left(\frac{w_{2}}{w_{1}}\right)+\alpha_{33} \ln \left(\frac{w_{3}}{w_{1}}\right)+\beta_{3 Y} \ln Y+\delta_{3 t} t+\varepsilon_{3}
\end{aligned}
$$

We estimate the equation system by Seemingly Unrelated Regression (SUR) as developed by Zellner (1962). As it is likely that the error terms are correlated within firms over cost shares, SUR is more efficient than estimating the equations separately with ordinary least squares (OLS). At the first stage, SUR uses equationby-equation OLS to obtain the covariance matrix of the error terms, $\Omega$. Then a feasible generalized least squares estimation is performed on the system of equations, conditional on $\Omega$.

As the summing-up condition necessitates one equation to be discarded, we use the maximum likelihood (ML) estimator fitted to SUR. The ML estimator is equivalent to iterating SUR until the changes in the estimated parameters and in $\Omega$ become arbitrarily small and has the appealing feature that results do not depend on the choice of cost share to be discarded.

\subsection{Data}

We use linked employer-employee data (LEED) to estimate the demand for differently skilled labor. The use of LEED is essential for our micro-level approach since it enables us to observe both individual skill-specific wages and firm-related informa- 
tion, such as output. The data is taken from the linked employer-employee dataset (LIAB) provided by the Institute of Employment Research (IAB) in Nuremberg, Germany (see Alda et al. (2005) for more information on the dataset).

The employee data are a sample of the administrative employment statistics of the German Federal Employment Agency (Bundesagentur für Arbeit), called the German employment register, which covers all employees paying social security contributions or receiving unemployment benefits (see Bender et al. (2000)). The public sector is excluded, as civil servants are rarely observed in the social security data. Employee information recorded in the data include wages, age, seniority, qualification, occupation, employment type (full-time, part-time or irregular employment), industry and region. We use the same skill definition as in the supply part of the model, differentiating between high, medium and low-skilled workers. Since we are interested in labor demand dependent on the skill level, individuals with missing information on qualification are excluded.

The firm component of the LIAB is the IAB Establishment Panel (cf. Kölling (2000)). The term 'establishment' refers to the fact that the observation unit is the individual plant, not the firm; there can be several plants per company. The Establishment Panel is a representative, stratified, random sample containing annual information on establishment structure and personnel decisions from 1993 onwards. It includes establishments with at least one worker for whom social contributions were paid, covering 16 industries and establishments from both the former West and East Germany.

We exclude mining, agricultural, finance sectors, as well as the public sector, since they measure turnover in a different way. Output is adjusted for inflation, using the German consumer price index obtained from the German Federal Statistical Office. Plants with missing information on output are excluded, as well as establishments with fewer than three workers in one of the three skill categories. Finally, we use survey weights provided in the LIAB to make the establishment sample representative for the whole population of German establishments. The final panel comprises 12 years (from 1996 to 2007) and 4,073 establishments, which are, on average, observed 3.3 times during the period studied. This results in 13, 451 establishment-year observations and between 1.6 and 2.0 million workers per year. 


\subsection{Labor demand elasticities}

We restrict the presentation of estimation results to the own-wage demand elasticities for the three skill types of workers. For a more thorough analysis and discussion of the effects of different specifications, see Peichl and Siegloch (2010). ${ }^{10}$ We find the highest own-wage elasticity is for the unskilled, at -1.05 , followed by the highskilled, at -0.56 , and the medium-skilled, at -0.37 . These results mirror the findings of previous studies on labor demand in Germany, such as Falk and Koebel (2001, 2004), Addison et al. (2008), Bauer et al. (2009), and Freier and Steiner (2010)). Firstly, all elasticities are negative and finite, as postulated by the theory and corroborate the claim that employment effects cannot be solely determined by labor supply shifts. Secondly, the absolute value of the own-wage elasticity of the unskilled is higher than the elasticity of the medium-skilled. Higher elasticities of unskilled workers are normally explained by globalization and international competition from low-wage countries, which destroy jobs for unskilled workers in industrial countries. As for the relationship between the high and medium-skilled, the empirical picture is somewhat ambiguous. In about half of the studies on Germany, the absolute value of high-skilled elasticities is greater than the value of the medium-skilled; in the other half, it is smaller. However, as far as the magnitude is concerned, most elasticities lie in the interval from -0.05 to -1.0 .

\section{Demand-supply link}

We now extend the labor supply model described in Section 3 to take into account labor demand adjustments based on the model described in Section 4. Figure 1 portrays the operating mode of the demand-supply link. Point $A$ depicts the labor market equilibrium. A policy reform shifts the labor supply to the right $\left(L S^{B}\right)$. Without a demand module, implicitly assuming a perfectly elastic labor demand, the resulting employment would rise to $E^{B}$. Assuming a downward-sloped labor demand curve, however, it is trivial to see that this cannot be the equilibrium of the labor market under perfect competition, since supply does not equal demand. Due to the wage elasticity, the rise in employment $\Delta E^{1}=E^{B}-E^{A}$ yields a decrease in the wage, $\Delta w^{1}=w^{C}-w^{A}$. We thus calculate $\Delta w^{1}$ using $\Delta E^{1}$ and the demand

\footnotetext{
${ }^{10}$ Some estimation results can be found in the Appendix. More detailed statistics are available on request.
} 
elasticity. We feed the new wage, $w^{C}$, into the supply model and recalculate the net income. The change in net income will again have an effect on labor supply, which is simulated using the behavioral labor supply module. Assuming a positive labor supply elasticity, the labor supply shifts to the left (from $L S^{B}$ to $L S^{D}$ ), reducing the initially positive employment effect. Once again using demand elasticities, this reduction of employment, $\Delta E^{2}=E^{D}-E^{B}$, will lead to an increase in the wage, $\Delta w^{2}=w^{E}-w^{C}$, shifting the supply curve to the right $\left(L S^{D}\right.$ to $\left.L S^{F}\right)$. This procedure is iterated until the employment shifts and thus the wage shifts become arbitrarily small ${ }^{11}$ and the model converges. At this point supply equals demand and the new market equilibrium is at point $Z$. We assume that the model converges instantaneously, i.e. within one period, which is why the intermediate stages of the iteration process are presented in grey.

As seen, different skill groups have different labor demand elasticities yielding different wage changes due to labor supply reactions. We consequently apply the iteration algorithm separately for each household type and skill group. The iteration algorithm for every household-type/skill combination is defined as follows:

To sum up, the iteration algorithm for every skill/household combination is defined as follows:

1) The change in net income due to the tax reform is calculated.

2) The labor supply effect is simulated, given the new net income.

3) The gross wage adjusts according to the supply effect and the labor demand function.

4) The labor supply effect is re-simulated given the new wage.

5) If the relative change in working hours is greater than 0.1 percent, repeat steps 3 and 4.

Some restrictive assumptions have to be made to justify the iteration algorithm. Most notably, the demand elasticity must be constant at any point of the demand curve. Furthermore, the assumptions of a perfectly competitive market must be

\footnotetext{
${ }^{11}$ We consider a relative change of worked hours of less than 0.1 percent to be sufficiently small. Depending on the size of the household-type/skill cell, this corresponds to between 400 and 7,000 full-time equivalents. The number of iterations necessary for convergence never exceeds 10 in our application.
} 


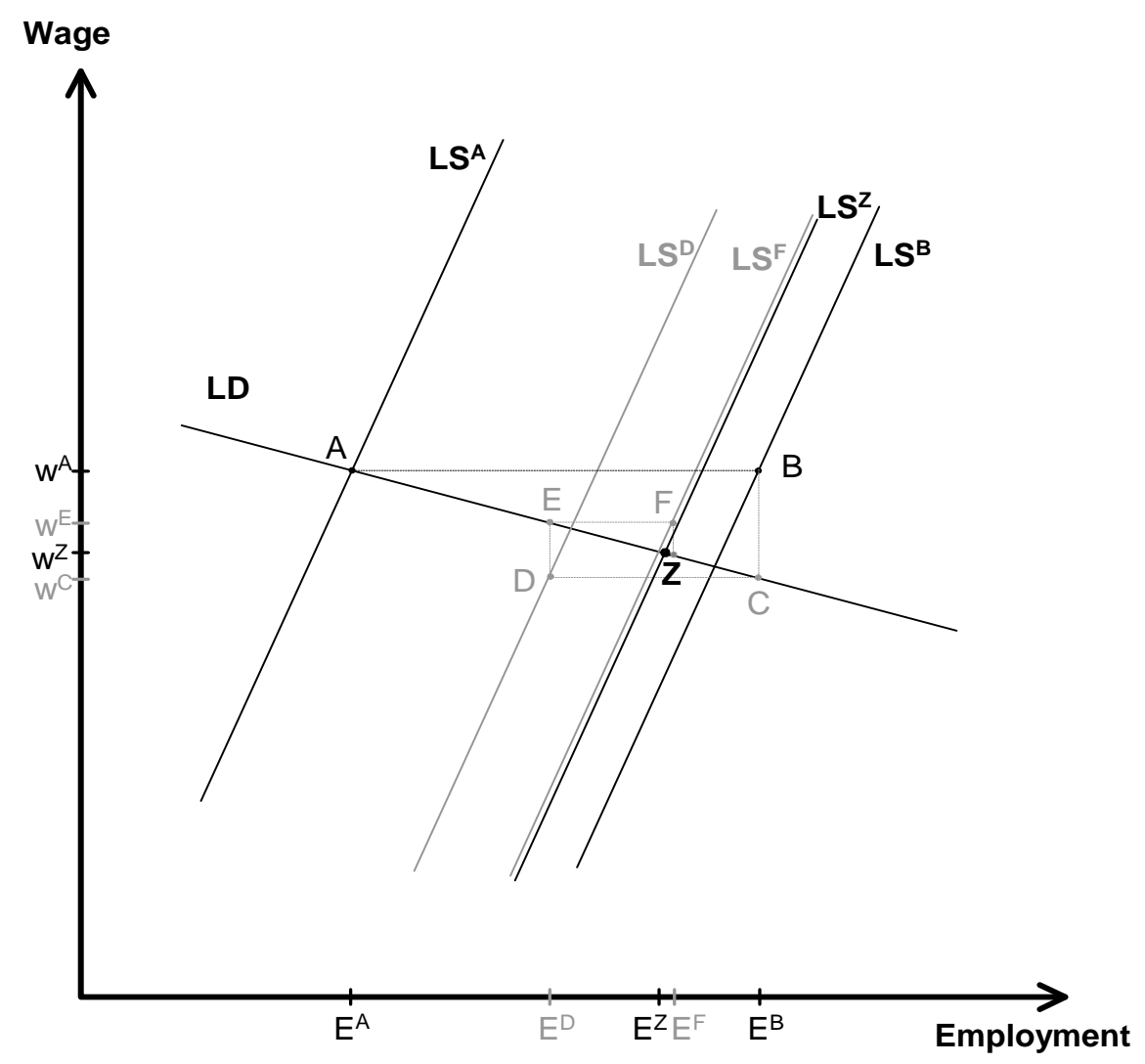

Figure 1: Supply and demand adjustments

fulfilled so that we are not faced with wage rigidities whatsoever. ${ }^{12}$ Last, as we want to demonstrate the importance of taking labor demand restrictions into account, we choose a pure labor supply side reform as a policy application. The demand side is assumed not to react to the policy change, so that the labor demand curve does not shift and the labor demand elasticities do not change. In principle, it is straightforward to extend the method presented here to allow for shifts in the labor demand curve as a reaction to policy changes.

\footnotetext{
${ }^{12}$ Note that this assumption is not crucial for the general method, which could be embedded into a different labor market model (e.g. union wage bargaining or efficiency wages).
} 


\section{Empirical application}

\subsection{Modeling workfare}

In order to demonstrate the effects of the labor supply-demand link, we simulate the effects of a counterfactual reform introducing the workfare concept for Germany. In principle, the workfare principle requires everybody who receives social benefits to work full-time (see Besley and Coate (1992), Torfing (1999), Moffitt (2002) and Ljungqvist $(1999,2010)$ ). Workfare concepts have been implemented in several countries, such as Denmark (cf. Torfing (1999)), the Netherlands, the UK and, under the label "Wisconsin Works" the US (cf. Ochel (2005) for a survey). In Germany, workfare has been widely discussed as an alternative to the current, generous social assistance system (see Sachverständigenrat zur Begutachtung der gesamtwirtschaftlichen Entwicklung (2005) and Bonin and Schneider (2006b)).

We choose the workfare concept as a counterfactual for several reasons. Firstly, there is very little evidence of the effects of workfare on labor supply and demand. Secondly, theory predicts an unambiguous, and therefore substantial, positive effect on the labor supply, as the choice of non-participation (and dependency on unemployment benefits) no longer agrees with the maximum amount of leisure. As the people in workfare have to work in a full-time community job to receive government transfers, they have the incentive to take up a regular job, which generally yields a higher income. Thirdly, due to the expected positive labor supply effects, positive fiscal effects are likely, which makes the counterfactual a viable reform proposal from a fiscal point of view. Finally, workfare concepts are often criticized for ignoring the possibility of demand restrictions. If the excess labor supply induced by the work requirement does not translate into regular employment, because the respective private sector labor demand does not exist, the intended reform effect does not materialize and the fiscal costs might increase substantially (see e.g. Peck and Theodore (2000)). ${ }^{13}$ This critique makes the reform a very appropriate counterfactual to illustrate the importance of taking labor demand effects into account.

In our application, we implement workfare as follows (cf. Sachverständigenrat zur Begutachtung der gesamtwirtschaftlichen Entwicklung (2005)): every employ-

\footnotetext{
${ }^{13}$ More normative arguments against workfare attack the concept from ethical points of view and on the grounds of fairness (see Peck and Theodore (2000)). Yet, recent behavioral experiments suggest that such regulations are perceived as fair in a Rawlsian state of the world (see Falk and Huffman (2007)).
} 
able individual who lives in a household that receives government benefits has to enroll in full-time community work for 40 hours per week. ${ }^{14}$ If the recipient is regularly employed but still relies to some extent on government transfers, the hours of mandatory community work is the difference between 40 hours and the regular weekly hours stated in the work contract. All other rules of the tax and benefit system remain unchanged.

\subsection{Simulation results}

The reform scenario is simulated with and without taking labor demand effects into account. Table 1 summarizes labor supply and labor demand effects of the reform by household type, skill level and gender. The first column of the table presents full-time equivalents (FTE) in the status quo. Column 2 reports the isolated labor supply effect without demand adjustments. Without labor demand adjustments the reform yields substantial and positive effect, increasing the labor supply by about 1.5 million full-time equivalents. As expected, labor supply responses are unambiguously positive across all household types and skill subgroups. Column 3 shows the effects of taking labor demand restrictions into account: the total increase in FTE is about 375, 000 lower than in the situation of pure labor supply adjustments. The overall offsetting effect of the labor demand restrictions (relative to the labor supply increase) is 25 percent (column 4). Labor demand effects countervail the positive labor supply effects for all household types, skill and gender groups, explaining the negative sign of the ratio between labor demand and labor supply, reported in last column of Table 1.

Hence, labor demand works as a stabilizer to employment shifts, as suggested by Figure 1. The magnitude of demand effects differs over household types, gender and skill groups but is substantive except for high-skilled workers. The higher relative offsetting effect for the medium-skilled is explained by two factors. Firstly, the labor supply effect of workfare on the low-skilled is relatively higher than the effect for the medium-skilled ( $25 \%$ increase vs. $5 \%$ ). Secondly, the labor demand elasticity of the low-skilled in absolute terms is higher, implying a smaller wage decrease for

\footnotetext{
${ }^{14}$ In Germany, there are two types of unemployment benefits: unemployment benefit I, which come from an insurance and unemployment benefit II, i.e. social assistance. Additionally, there are housing benefits (Wohngeld) and subsidiary child benefits (Kinderzuschlag), which can be substitutes for social assistance and are consequently subject to the workfare rules as well. For details on the German benefit system, see Peichl et al. (2010).
} 
Table 1: Labor demand effects by household-type, skill and gender

\begin{tabular}{l|rrrr}
\hline \hline HH-Type & FTE base & LS effect & LD effect & LD/LS effect (\%) \\
\hline SingM & 5192.6 & 422.6 & -103.6 & -24.51 \\
SingF & 4904.2 & 311.2 & -74.8 & -24.02 \\
CoupM & 12188.9 & 161.5 & -19.9 & -12.29 \\
CoupF & 8075.9 & 595.7 & -179.2 & -30.09 \\
\hline H-ski & 8789.9 & 14.7 & -0.6 & -3.81 \\
M-ski & 19186.0 & 876.2 & -272.1 & -31.05 \\
L-ski & 2385.7 & 600.2 & -104.8 & -17.46 \\
\hline Male & 17381.4 & 584.2 & -123.4 & -21.13 \\
Female & 12980.0 & 906.9 & -254.0 & -28.01 \\
\hline Overall & $\mathbf{3 0 3 6 1 . 5}$ & $\mathbf{1 4 9 1 . 1}$ & $\mathbf{- 3 7 7 . 4}$ & $\mathbf{- 2 5 . 3 1}$ \\
\hline
\end{tabular}

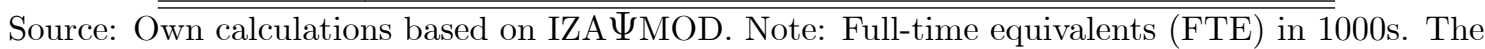
LS effect measures the difference in FTE to the status quo, whereas the LD effect measures the difference to the LS effect.

a given increase in employment. Looking at gender differences, Table 1 shows that countervailing effect of demand effects are stronger for women $(-28 \%$ vs. $-21 \%)$. As the skill distribution over gender is comparable, the difference is due to different labor supply elasticities. Women, especially couples, have higher supply elasticities and decrease their labor supply to a larger extent when the wage decreases as a consequence of the demand effect.

In order to open the black box, we demonstrate the iteration of hours changes and wage adjustments for two examples. Table 2 presents the iteration process for medium and low-skilled women, living in couples. The numerical results accurately mirror the graphical representation of Figure 1. Wage and hour changes are alternating in sign, due to the negative demand elasticities, and changes become smaller as the models converges. Furthermore, the table shows that the model converges more quickly for low-skilled women; after three iteration steps the relative change in hours is less than 0.1 percent, and therefore beneath the convergence criterion. For the medium-skilled, in contrast, the model iterates seven times until convergence is achieved.

The example illustrates the role of different elasticities. Although the initial percentage changes in hours are much larger for unskilled females (25\% vs. $7 \%$ ), the model converges much more quickly due to the higher demand elasticities for the low-skilled, since a given hour change can be induced by a relatively smaller wage change. Thus, the less elastic the labor demand, the slower the convergence of the 
model.

Table 2: Iteration process - Women in couples

\begin{tabular}{l|rr|rr}
\hline \hline Iteration & \multicolumn{2}{|c|}{ Medium-skilled } & \multicolumn{2}{c}{ Low-skilled } \\
No & $\Delta$ Hour (\%) & $\Delta$ Wage $(\%)$ & $\Delta$ Hour (\%) & $\Delta$ Wage $(\%)$ \\
\hline 1 & 7.29 & -19.71 & 24.96 & -23.77 \\
2 & -3.63 & 9.80 & -4.09 & 3.90 \\
3 & 1.86 & -5.02 & 0.48 & -0.46 \\
4 & -0.98 & 2.64 & -0.08 & 0.08 \\
5 & 0.43 & -1.16 & 0.02 & -0.02 \\
6 & -0.14 & 0.40 & -0.00 & 0.00 \\
7 & 0.03 & -0.08 & 0.00 & -0.00 \\
\hline \hline
\end{tabular}

As far as fiscal effects are concerned, table 3 shows that the workfare reform does indeed increase the government budget - due to the unambiguously positive labor supply effect and the resulting increases in tax and social insurance payments, combined with decreases in benefit payments. The table shows that the government budget increases by 31.7 billion euros, which - for the population sample corresponds to approximately 9.4 percent. The countervailing demand effect, of course, reduces this positive budget effect to 27.7 billion euros (8.2\%) compared to the status quo. Nonetheless, the government has to finance the community-jobs for those people who remain dependent on government transfers. There are no clear estimates on how much these jobs would cost. Fuest and Peichl (2008) calculate annual administrative costs of about 4,200 euros per job, referring to estimations of the German Federal Employment Agency. The simulation results suggest that after labor supply adjustments, 3.8 million people would receive benefits and be required to work in a community job. ${ }^{15}$ If we take into account the demand model the number even increases to 4.1 million people employed in the workfare program. Hence, using a pure labor supply model, the net effect on government budget yields approximately 15.7 billion euros. When taking demand restrictions into account, the positive budget effect shrinks to 10.5 billion euros.

Thus, the workfare reform increases government revenues and is feasible from a fiscal point of view. This is even more true, as the positive budget effect is a conservative estimate for mainly three reasons. Firstly, we overestimate the number

\footnotetext{
${ }^{15}$ Note that in the baseline the number of hypothetical individuals in workfare, i.e. the employable people receiving some kind of government transfers, is 5.4 million.
} 
Table 3: Fiscal effects

\begin{tabular}{|c|c|c|c|}
\hline \multirow[b]{2}{*}{ Changes } & After LS & \multicolumn{2}{|c|}{ After LS \& LD } \\
\hline & in billion $€$ in & in billion $€$ & in $\%$ \\
\hline Tax revenue & $1.2 \quad 0$ & 0.9 & 0.7 \\
\hline Social insurance contributions & 15.4 & 13.4 & 4.5 \\
\hline Benefit payments & 15.1 & 13.4 & 15.2 \\
\hline Budget effect & 31.7 & 27.7 & 8.2 \\
\hline Persons in workfare (in millions) & 3.8 & 4.1 & \\
\hline Costs of workfare & 16.0 & 17.2 & - \\
\hline Total effect & 15.7 & 10.5 & - \\
\hline
\end{tabular}

of benefit recipients, as we are not able to model benefit take-up rates in a reliable way. Secondly, there might be some people choosing not to take up community work (foregoing benefit payments). Thirdly, the full-time equivalent occupation does not necessarily have to be a community job. The work requirement could also be fulfilled by participating in a training program or by more actively applying for new jobs. Consequently, it is very likely that the number of jobs created is substantially smaller, making the reform even more feasible when accounting for demand effects.

\subsection{Robustness checks}

In order to test both the theoretical and empirical reliability of our approach, we perform several robustness checks. Firstly, we check the plausibility of the model with respect to different labor demand elasticities. We compare the baseline scenario with a low and a high-elasticity scenario. In the high (low) scenario, we increase (decrease) the own-wage elasticities presented in Section 4.3 by 20 percent. Table 4 summarizes the results.

It becomes evident that the higher the elasticities are in absolute terms, the smaller the offsetting demand effect (LS/LD). This finding confirms the insight obtained from examining the convergence pattern by skill type presented in Section 6.2. As expected, Table 4 shows that the model converges more quickly for all household types if the absolute value of the elasticity is higher.

This result is in line with the theory and can be best explained graphically. Figure 2 is a simplification of the iteration process described in Figure 1 and shows the effect of a tax reform in presence of a low and high-elasticity demand curve ( $L D^{L}$ and $L D^{H}$ ). In the $L D^{L}$-case, the wage reduction and the countervailing labor 
Table 4: Elasticity sensitivity

\begin{tabular}{l|cc|cc|cc}
\hline \hline & \multicolumn{2}{|c|}{ Low-elasticity scenario } & \multicolumn{2}{c|}{ Baseline scenario } & \multicolumn{2}{c}{ High-elasticity scenario } \\
HH-Type & LS/LD effect & Iterations & LS/LD effect & Iterations & LS/LD effect & Iterations \\
\hline SingM & -29.84 & 5 & -24.51 & 5 & -20.89 & 4 \\
SingF & -29.70 & 6 & -24.02 & 6 & -19.46 & 5 \\
CoupM & -13.73 & 4 & -12.29 & 3 & -10.40 & 3 \\
CoupF & -38.64 & 9 & -30.09 & 7 & -25.44 & 6 \\
\hline Overall & $\mathbf{- 3 1 . 5 8}$ & & $\mathbf{- 2 5 . 3 1}$ & & $\mathbf{- 2 1 . 2 7}$ & \\
\hline \hline
\end{tabular}

Source: Own calculations based on IZA $\Psi$ MOD. Note: Low/high-elasticity scenarios refer to elasticities in absolute terms.

demand effect is higher than in the $L D^{H}$-case. The rationale behind this graphical finding is the following: if labor demand is more elastic, a given change in working hours can be achieved with a smaller change in the wage. Let us assume a fixed rise in working hours due to a tax reform. The higher the absolute value of the ownwage demand elasticity, the smaller is the wage decrease necessary to induce such a change in working hours. With the iteration process described above, this implies that the wage reactions and thus the effects of the demand module are smaller. As a result, the model also converges more quickly.

As a second robustness check, we simulated several other reform scenarios (for instance, different versions of flat tax reforms which both increase or decrease government budget as well as revenue neutral scenarios). In all cases, the labor demand works as a stabilizer for the supply response, also when the initial tax reform reduces labor supply. In other words, if labor supply falls due to a reform, demand adjustments temper this effect, so that the resulting employment effect is less negative than the initial labor supply reaction. Moreover, we find that the offsetting labor demand effects are relatively stable and lie in the range of 15 to 35 percent, depending on the specific reform simulated and the size of the labor demand elasticities.

Third, we check the sensitivity of our results with respect to the specification of the labor supply and the labor demand model. We find that the (qualitative) results are independent of the concrete specification of the utility function. Also, the number of discrete labor supply choices and the method employed to calculate the residuals of the random utility model only marginally affect the quantitative results. As for the demand model, labor demand elasticities are robust with respect to the underlying cost function, the returns to scale and the inclusion of capital treated as a quasi-fixed input factor. 


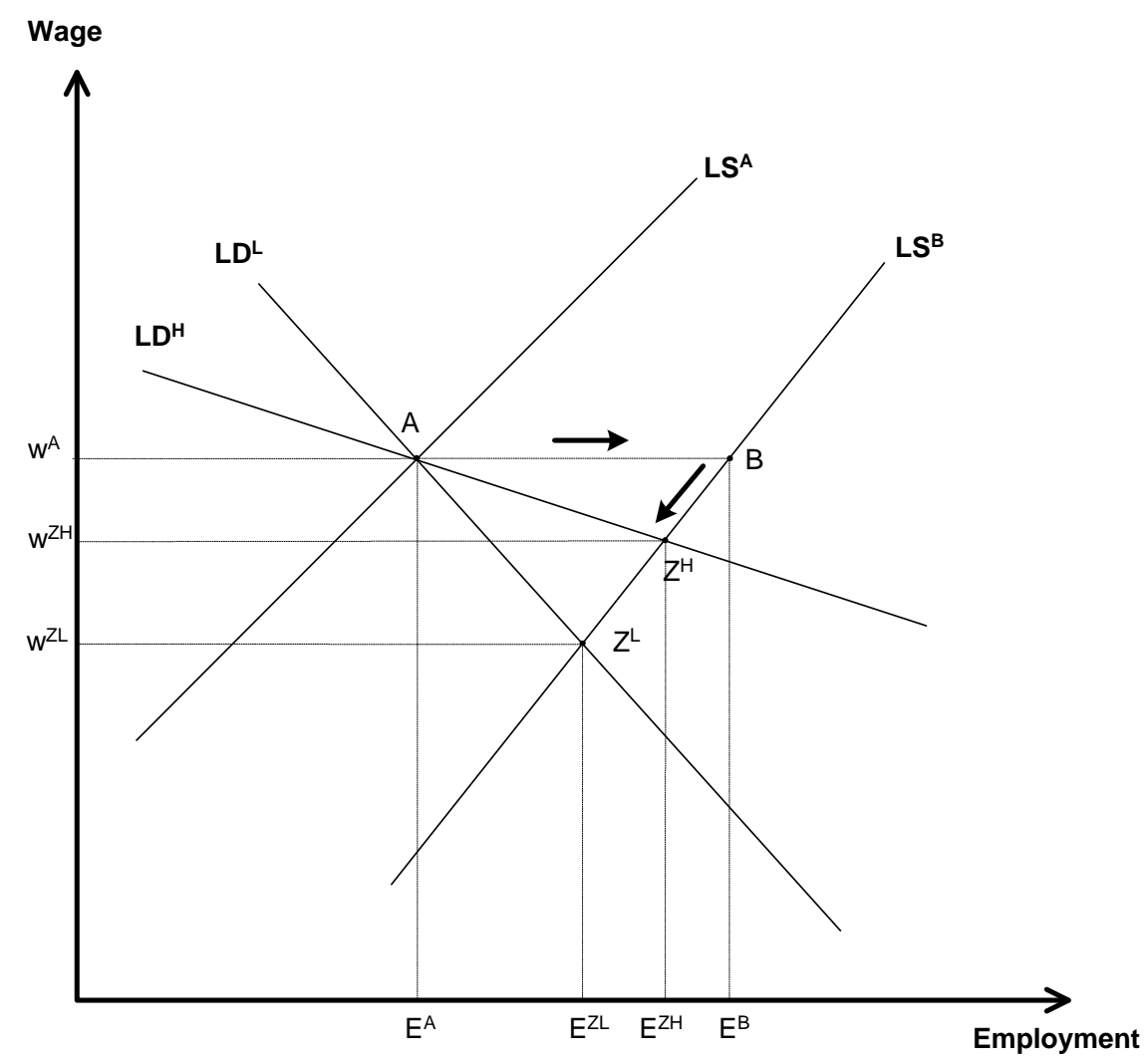

Figure 2: The role of different elasticities

\section{Conclusions}

Structural labor supply models are an important tool for the evaluation of policy reforms. Yet, most of the models ignore the demand side of the labor market. They either assume a perfectly elastic labor demand curve, so that labor supply effects are assumed to be equal to the employment effect, or simply restrict the analysis to the supply side. Employing a newly developed demand model based on detailed, linked employer-employee data for Germany, we show that, in line with earlier findings, labor demand is not at all perfectly elastic, but demand elasticities are finite, ranging from -0.37 to -1.05 . It immediately follows that labor market estimates obtained from pure labor supply models are biased. Ex-ante policy evaluation studies must account for demand effects in order to produce reliable results.

In this paper, we propose a straightforward method to meet this necessity. We build a demand-supply link that iterates labor supply and demand adjustments until 
the partial labor market equilibrium is achieved. We make use of the estimated labor demand elasticities and calculate how a labor supply shift affects the gross wage. We then re-estimate labor supply effects, given the adjusted wages. This loop is repeated until the model converges.

In order to demonstrate the performance of our supply-demand link, we introduce a workfare reform for Germany, a counterfactual that yields unambiguously positive labor supply effects, while increasing the government budget. We find that labor demand plays a crucial role for the assessment of the policy reform. On average, labor demand adjustments offset the positive labor supply effect of the reform by 25 percent. Instead of leading to a pure LS-effect of around 1.5 million, new, full-time jobs, the reform would yield roughly 1.1 million new jobs. Although the reduction of the initially positive labor supply effects reduces government revenues, the reform still has a positive effect on government budget, making the reform proposal feasible from a fiscal point of view.

The new demand-supply link is an important extension for structural labor supply models. It makes employment predictions more accurate and consequently exante policy recommendations more reliable. Moreover, the proposed method has several advantages compared to existing approaches taking into account demand restrictions, such as Double Hurdle or CGE models. Our approach is general enough to be used in combination with any labor supply model; it is parsimonious as we restrict the analysis to the labor market; it accounts for heterogeneity, as we remain at the micro-level, which enables us to identify the precise adjustment process.

Nevertheless, there are shortcomings to the approach, which have to be addressed in future research. It would be desirable to not only attach a demand extension to an existing labor supply model but also to assume an integrated and comprehensive labor market model. This would enable us to relax the relatively strong assumption of a perfectly competitive labor market and to impose rigidities caused by, for example, efficiency wages, labor unions or search frictions. When assuming an integrated labor market, it would also be possible to allow labor demand to react to a tax reform and the induced supply changes. ${ }^{16}$ In such a framework, the demand curve would shift and these shifts would have to be part of the iteration process as well.

\footnotetext{
${ }^{16}$ At the moment, this kind of simultaneity is, however, hard to achieve due to practical reasons, as the usage of the LIAB dataset is only possible via remote access, making an iteration process for the labor demand prohibitively time consuming and unviable from a programmer's point of view.
} 


\section{References}

Aaberge, R., Colombino, U. and Strøm, S. (2000), 'Labour Supply Responses and Welfare Effects from Replacing Current Tax Rules by a Flat Tax: Empirical Evidence from Italy, Norway and Sweden', Journal of Population Economics $\mathbf{1 3}(4), 595-621$.

Aaberge, R., Colombino, U. and Strøm, S. (1999), 'Labour Supply in Italy: An Empirical Analysis of Joint Household Decisions, with Taxes and Quantity Constraints', Journal of Applied Econometrics 14(4), 403-422.

Aaberge, R., Dagsvik, J. and Strøm, S. (1995), 'Labor Supply Responses and Welfare Effects of Tax Reforms', Scandinavian Journal of Economics 97(4), 635-659.

Addison, J. T., Bellmann, L., Schank, T. and Teixeira, P. (2008), 'The Demand for Labor: An Analysis Using Matched Employer-Employee Data from the German LIAB. Will the High Unskilled Worker Own-Wage Elasticity Please Stand Up?', Journal of Labor Research 29(2), 114-137.

Alda, H., Bender, S. and Gartner, H. (2005), 'European Data Watch: The Linked Employer-Employee Dataset of the IAB (LIAB)', Schmollers Jahrbuch: Journal of Applied Social Science Studies 125(2), 327-336.

Arntz, M., Boeters, S., Gürtzgen, N. and Schubert, S. (2008), 'Analysing Welfare Reform in a Microsimulation-AGE Model: The Value of Disaggregation', Economic Modelling 25(3), 422-439.

Bargain, O., Caliendo, M., Haan, P. and Orsini, K. (2010), "Making Work Pay" in a Rationed Labor Market', Journal of Population Economics 23(1), 323-351.

Bauer, T. K., Kluve, J., Schaffner, S. and Schmidt, C. M. (2009), 'Fiscal Effects of Minimum Wages: An Analysis for Germany', German Economic Review $\mathbf{1 0}(2), 224-242$.

Bender, S., Haas, A. and Klose, C. (2000), 'The IAB Employment Subsample 1975-1995', Schmollers Jahrbuch: Journal of Applied Social Science Studies $\mathbf{1 2 0}(4), 649-662$. 
Besley, T. and Coate, S. (1992), 'Workfare Versus Welfare: Incentive Arguments for Work Requirements in Poverty-Alleviation Programs', The Amercian Economic Review 82(1), 249-261.

Bloemen, H. G. (2000), 'A Model of Labour Supply with Job Offer Restrictions', Labour Economics 7(3), 297-312.

Blundell, R., Brewer, M., Haan, P. and Shephard, A. (2009), 'Optimal Income Taxation of Lone Mothers: An Empirical Comparison of the UK and Germany', The Economic Journal 119(535), F101-F121.

Blundell, R., Duncan, A., McCrae, J. and Meghir, C. (2000), 'The Labour Market Impact of the Working Families' Tax Credit', Fiscal Studies 21(1), 75-104.

Blundell, R., Ham, J. and Meghir, C. (1987), 'Unemployment and Female Labour Supply', The Economic Journal 97(338a), 44-46.

Boeters, S. and Feil, M. (2009), 'Heterogeneous Labour Markets in a Microsimulation-AGE Model: Application to Welfare Reform in Germany', Computational Economics 33(4), 305-335.

Boeters, S., Feil, M. and Gürtzgen, N. (2005), 'Discrete Working Time Choice in an Applied General Equilibrium Model', Computational Economics 26(3-4), 1-29.

Bonin, H. and Schneider, H. (2006a), 'Analytical Prediction of Transition Probabilities in the Conditional Logit Model', Economic Letters 90(1), 102-107.

Bonin, H. and Schneider, H. (2006b), 'Workfare: Eine wirksame Alternative zum Kombilohn', IZA Discussion Paper No. 2399.

Bourguignon, F., Robilliard, A.-S. and Robinson, S. (2003), 'Representative Versus Real Households in the Macro-Economic Modelling of Inequality', DIAL Document de Travail DT/2003-10.

Bovenberg, A. L., Graafland, J. J. and de Mooij, R. A. (2000), 'Tax Reform and the Dutch Labor Market: An Applied General Equilibrium Approach', Journal of Public Economics 78(1-2), 193-214.

Christensen, L. R., Jorgenson, D. W. and Lau, L. J. (1973), 'Transcendental Logarithmic Production Frontiers', The Review of Economics and Statistics $\mathbf{5 5}(1), 28-45$. 
Creedy, J. and Duncan, A. (2005), 'Aggregating Labour Supply and Feedback Effects in Microsimulation', Australian Journal of Labour Economics 8(3), 277-290.

Creedy, J. and Kalb, G. (2005), 'Discrete Hours Labour Supply Modelling: Specification, Estimation and Simulation', Journal of Economic Surveys 19(5), 697-734.

Diewert, W. E. and Wales, T. J. (1987), 'Flexible Functional Forms and Global Curvature Conditions', Econometrica 55(1), 43-68.

Duncan, A. and Weeks, M. (1998), 'Simulating Transitions Using Discrete Choice Models', Proceedings of the American Statistical Association 106, 151-156.

Eissa, N. and Hoynes, H. (2004), 'Taxes and the Labor Market Participation of Married Couples: The Earned Income Tax Credit', Journal of Public Economics 88(9-10), 1931-1958.

Falk, A. and Huffman, D. (2007), 'Studying Labor Market Institutions in the Lab: Minimum Wages, Employment Protection and Workfare', Journal of Institutional and Theoretical Economics 163(1), 30-45.

Falk, M. and Koebel, B. (2001), 'A Dynamic Heterogeneous Labour Demand Model for German Manufacturing', Applied Economics 33(3), 339-348.

Falk, M. and Koebel, B. M. (2004), 'The Impact of Office Machinery, and Computer Capital on the Demand for Heterogenous Labour', Labour Economics 11(1), 99117.

Freier, R. and Steiner, V. (2010), "Marginal employment" and the Demand for Heterogeneous Labour: Elasticity Estimates from a Multi-Factor Labour Demand Model for Germany', Applied Economics Letters 17(12), 1177-1182.

Fuest, C. and Peichl, A. (2008), 'Grundeinkommen vs. Kombilohn: Beschäftigungsund Finanzierungswirkungen und Unterschiede im Empfängerkreis', Jahrbuch für Wirtschaftswissenschaften 59(2), 94-113.

Haan, P. and Steiner, V. (2006), Labor Market Effects of the German Tax Reform 2000, in C. Dreger, H. P. Galler and U. Walwei, eds, 'Determinants of Employment', Nomos, Baden-Baden, pp. 101-117.

Hamermesh, D. S. (1993), Labor Demand, Princeton University Press, Princeton. 
Heim, B. T. (2007), 'The Incredible Shrinking Elasticities: Married Female Labor Supply, 1978-2002', The Journal of Human Resources 42(4), 881-918.

Heim, B. T. (2009), 'Structural Estimation of Family Labor Supply with Taxes: Estimating a Continuous Hours Model Using a Direct Utility Specification', The Journal of Human Resources 44(2), 350-385.

Hogan, V. (2004), 'The Welfare Cost of Taxation in a Labour Market with Unemployment and Non-Participation', Labour Economics 11(4), 395-413.

Hoynes, H. (1996), 'Welfare Transfers in Two-Parent Families: Labor Supply and Welfare Participation Under the AFDC-UP', Econometrica 64(2), 295-332.

Hérault, N. (2010), 'Sequential Linking of Computable General Equilibrium and Microsimulation Models: A Comparison of Behavioural and Reweighting Techniques', International Journal of Microsimulation 3(1), 35-42.

Immervoll, H., Kleven, H., Kreiner, C. and Saez, E. (2007), 'Welfare Reform in European Countries: A Microsimulation Analysis', The Economic Journal $\mathbf{1 1 7}(516), 1-44$.

Kölling, A. (2000), 'The IAB-Establishment Panel', Schmollers Jahrbuch: Journal of Applied Social Science Studies 120(2), 291-300.

Laroque, G. and Salanié, B. (2002), 'Labour Market Institutions and Employment in France', Journal of Applied Econometrics 17(1), 25-48.

Ljungqvist, L. (1999), 'Squandering European Labour: Social Safety Nets in Times of Economic Turbulence', Scottish Journal of Political Economy 46(4), 367-388.

Ljungqvist, L. (2010), 'Unemployment Crisis - Challenge and Opportunity', CESifo Forum 1, 7-13.

McFadden, D. (1973), Conditional Logit Analysis of Qualitative Choice Behavior, in P. Zarembka, ed., 'Frontiers in Econometrics', Academic Press, New York, pp. $105-142$.

Meyer, R. H. and Wise, D. A. (1983a), 'Discontinuous Distributions and Missing Persons: The Minimum Wage and Unemployed Youth', Econometrica 51(6), 16771698. 
Meyer, R. H. and Wise, D. A. (1983b), 'The Effects of the Minimum Wage on the Employment and Earnings of Youth', Journal of Labor Economics 1(1), 66-100.

Moffitt, R. A. (1982), 'The Tobit Model, Hours of Work and Institutional Constraints', The Review of Economics and Statistics 64(3), 510-515.

Moffitt, R. A. (2002), Welfare Programs and Labor Supply, in A. J. Auerbach and M. Feldstein, eds, 'Handbook of Public Economics', Vol. 4, Elsevier, Amsterdam, pp. 2393-2430.

Ochel, W. (2005), 'Welfare-to-Work Experiences with Specific Work-First Programmes in Selected Countries', International Social Security Review 58(4), 6793.

Peck, J. and Theodore, N. (2000), "Work First": Workfare and the Regulation of Contingent Labour Markets', Cambridge Journal of Economics 24(1), 119-138.

Peichl, A. (2009), 'The Benefits and Problems of Linking Micro and Macro Models: Evidence from a Flat Tax Analysis for Germany', Journal of Applied Economics $\mathbf{1 2}(2), 301-329$.

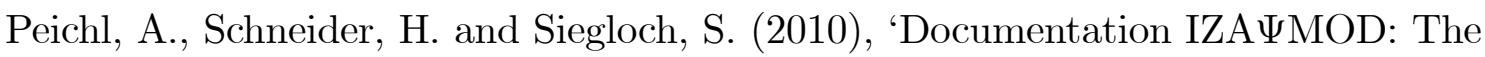
IZA Policy SImulation MODel', IZA Discussion Paper No. 4865.

Peichl, A. and Siegloch, S. (2010), 'Labor Demand for Germany: A Critical Review', mimeo.

Sachverständigenrat zur Begutachtung der gesamtwirtschaftlichen Entwicklung (2005), Jahresgutachten 2005/2006: Die Chance nutzen - Reformen mutig voranbringen, Metzler-Poeschel, Stuttgart.

Saez, E. (2001), 'Using Elasticities to Derive Optimal Income Tax Rates', Review of Economic Studies 68(1), 205-229.

Shephard, R. W. (1970), The Theory of Cost and Production Functions, Princeton University Press, Princeton.

Torfing, J. (1999), 'Workfare with Welfare: Recent Reforms of the Danish Welfare State', Journal of European Social Policy 9(1), 5-28. 
Tummers, M. P. and Woittiez, I. (1991), 'A Simultaneous Wage and Labor Supply Model with Hours Restrictions', The Journal of Human Resources 26(3), 393423.

van Soest, A. (1995), 'Structural Models of Family Labor Supply: A Discrete Choice Approach', The Journal of Human Resources 30(1), 63-88.

van Soest, A., Woittiez, I. and Kapteyn, A. (1990), 'Labor Supply, Income Taxes, and Hours Restrictions in the Netherlands', The Journal of Human Resources $\mathbf{2 5}(3), 517-558$.

Wagner, G. G., Frick, J. R. and Schupp, J. (2007), 'The German Socio-Economic Panel (SOEP) - Scope, Evolution and Enhancements', Schmollers Jahrbuch: Journal of Applied Social Science Studies 127(1), 139-169.

Zellner, A. (1962), 'An Efficient Method of Estimating Seemingly Unrelated Regressions and Tests of Aggregation Bias', Journal of the American Statistical Association 57(298), 348-368. 


\section{A Appendix}

Table 5: Estimation statistics of demand model

Model statistics

Observations

11472

Log pseudolikelihood $\quad 225609.8$

Wald $\mathrm{chi}^{2}$

74.10

Prob $>\mathrm{chi}^{2}$

0.0000

Theoretical fit

$\begin{array}{ll}\text { Pred. cost shares }<0 & 0\end{array}$

$\%$ strict quasi-concavity $\quad 1.0$

\begin{tabular}{lrr} 
Estimates & Coefficient & Robust Standard Error \\
\hline$\alpha_{2}$ & -0.5180659 & 2.332513 \\
$\alpha_{3}$ & 4.100664 & 2.192922 \\
$\alpha_{22}$ & -0.0435001 & 0.037398 \\
$\alpha_{23}$ & 0.0581057 & 0.0302462 \\
$\alpha_{32}$ & 0.0581057 & 0.0302462 \\
$\alpha_{33}$ & -0.0301589 & 0.0262384 \\
$\beta_{2 Y}$ & 0.0050241 & 0.0041294 \\
$\beta_{3 Y}$ & -0.0067779 & 0.0041272 \\
$\delta_{2 t}$ & 0.0005713 & 0.001171 \\
$\delta_{3 t}$ & -0.0019055 & 0.0011008 \\
$d_{2 \text { IConstruction }}$ & 0.0107481 & 0.0217273 \\
$d_{3 \text { IConstruction }}$ & -0.0135479 & 0.0240063 \\
$d_{2 \text { ITrafficComm }}$ & 0.071256 & 0.0196612 \\
$d_{3 \text { ITrafficComm }}$ & -0.0612755 & 0.0143868 \\
$d_{2 \text { IServices }}$ & 0.0201532 & 0.0160792 \\
$d_{3 \text { IServices }}$ & -0.0640076 & 0.0102079 \\
\hline \hline
\end{tabular}

